\title{
Butterfly farming in Papua New Guinea
}

\author{
Angus F. Hutton
}

Papua New Guinea takes insect conservation seriously, and for 10 years now has involved hundreds of villagers in an innovative butterfly farming scheme, which benefits both people and wildlife. Angus Hutton, who was National Co-ordinator for the project at its inception, describes this successful integration of conservation with development.

Alfred Russel Wallace in his treatise The Malay Archipelago (1869) first drew the attention of naturalists to the amazing arthropods of the Papuan Region, and this was followed by many collecting expeditions. The most famous collector was probably A. S. Meek, on behalf of Walter Rothschild in 1915. Later waves of collectors came, some scientific, but mostly motivated by profits that could be obtained in Europe, America and elsewhere for spectacular butterflies, moths, beetles and other insects. This trade escalated until the mid-1960s, when the Government introduced the Fauna Protection Ordinance (1966) declaring seven endangered species of Ornithoptera (birdwing butterflies) totally protected. Following many court convictions, several expatriate dealers and traders fled the country or were deported. Expatriate dealings and profiteering in insects were virtually abolished, with legislation introduced in 1974 restricting trade to Papua New Guineans. At the same time, the Government, through its Division of Wildlife, started the Insect Farming, Trading and Conservation Project. Its objectives were to educate and assist interested farmers so that they could meet the demand for insects and benefit financially. At the same time, environment-enrichment programmes were started, research was carried out, and efforts were made to improve quality, 158 labelling and marketing and, by controlled harvesting, to reduce the impact on wild-caught specimens.

Now, after 10 years of operation, there are more than 500 butterfly farmers in all 10 provinces of Papua New Guinea. They rear butterflies, beetles, stick and leaf insects, moths and other insects for export all over the world. These are handled through the Insect Farming and Trading Agency (IFTA), which was established in 1978 as a non-profit government organisation to act as a vital link between the farmers and buyers overseas. Its main aims are quality control and price standardisation. It buys from the farmers, who are paid promptly, sorts and labels specimens, and makes up the overseas orders, with specimens that could come from 50 or more diverse areas. The 25 per cent mark-up on export prices covers the operating costs of the Agency, which also supplies farmers with equipment, chemicals, seeds of food plants and so on.

A Papua New Guinean finds it strange that people are prepared to pay, and pay well, for insects. In terms of weight, insects are far more valuable than cattle and, indeed, almost as valuable as gold. Each year the demand for butterflies is rising; millions are caught throughout the world and sold to dealers, entomologists, museums, private collectors, students and, probably most of all, to ordinary people. Many are mounted as 'curios' and used as decoration, but these are mostly common species and usually originate from factory-like operations based in Taiwan, Korea, Hong Kong and Malaysia. However, in Papua New Guinea this kind of operation does not go on. Specimens are sold with full scientific

Oryx Vol 19 No 3 
data and are recognised internationally as prime specimens in the insect trade; consequently, they are highly regarded and paid for accordingly.

Most Papua New Guineans in the remotest villages know and understand the habits, locations and life histories of the wildlife around them, and depend on this knowledge to a very great extent in order to continue their traditional way of life. Introducing insect farming as a means of participating in a cash economy does not, therefore, involve any great disruption of lifestyle. Butterfly farmers work as and when they wish; age is no barrier, there are no dangers, the work is not hard and there are no deadlines. No capital is required, no fencing is needed to enclose the livestock and, most important of all, the natural vegetation does not need to be cleared as it does with traditional plantation crops like rubber, tea, coffee, cocoa and coconuts. It costs under A $\$ 10.00$ to set a farmer up in business for the first time. This is for certain essential chemicals, papers, forceps, a couple of metres of fly wire and some black plastic for a solar drier, and the postage on his first consignment of insects to the Agency.

\section{The butterfly farm}

Butterfly farms are usually established in areas of traditionally owned land, often too steep for food gardens or cultivation. They may also be set up in old abandoned garden areas. Areas of virgin forest, particularly where there is a swamp or watercourse with sandbanks and open patches where the sun can penetrate, are highly suitable. An hour or two spent in such places will produce an amazing inventory of species; all that is then needed is to induce them to remain. This is done by planting large numbers of the various species of larval food plants in the area, together with nectar-producing plants such as Hibiscus and a whole range of other flowering shrubs and vines. In Papua New Guinea, Aristolochia vines are most important as their many species are the only larval food plants of the Omithoptera or birdwing butterflies, which are found throughout the country and are highly sought by collectors. The enriched habitat becomes a place where wild butterflies find everything they need to reproduce and so, without the use of fences, the farmer Butterfly farming in Papua New Guinea retains a resident stock of breeding butterflies. By planting varied species of food plants he can maintain colonies of many butterfly species. Many farmers have established successful farms in areas where the original habitat was destroyed by logging or natural disasters (cyclones and volcanic eruptions), and then reintroduced livestock in the form of pupae from surrounding areas. The emerging adults adopted the farm as their 'home' and formed the nucleus stock.

As insects are so prolific, once the farm has been established the farmer seldom needs to collect from anywhere else, virtually eliminating the need for harvesting wild butterflies. Some farms have been so successful that the resultant population explosions have caused problems of overstocking, and larvae have had to be transferred to other areas. Many schools in Papua New Guinea have a butterfly farm as part of their activities, often on land donated by villagers. This provides the students with a living biology laboratory and also generates a cash income for the purchase of equipment, books, projectors and so on. Many teachers, initially trained by wildlife officers, when transferred to new schools in other areas immediately start up a butterfly farm and so the industry progresses. It is largely selfgenerating. Some of the vocational training schools have turned their skills to making simple solar driers for the farmers, while others have produced frames and cabinets of mounted specimens for the lucrative tourist trade.

While much mention has been made of butterflies, there is also a very large interest and trade in other insects, particularly beetles, many of which compete for the same larval food plants; for this reason, many are collected in the wild from forest areas surrounding butterfly farms. Many species of stick and leaf insects are easily reared, many on Guava plants, and several species of large beetles can be reared on Ficus sp., breadfruit Artocarpus communis and Pandanus spp. When first starting their farms, most farmers concentrate on insects other than butterflies and moths while they wait for the food plants to grow. During this period, they have to be particularly careful only to allow minimal larval populations on young plants, or these would be eaten to the roots before they were sufficiently well grown to support larvae. Some farmers grow their plants in bamboo pots 
or woven baskets to make management easier, particularly in the very early stages from ova to first or second instar when predators can be a problem. Most farmers have a small nursery to propagate food plants from seeds or cuttings, and enclose it with netting, deliberately excluding butterflies to ensure unrestricted plant growth.

It is essential that the farms be protected from livestock such as pigs, cattle and poultry, as these can cause severe damage. A thick hedge of Bougainvillea, with Hibiscus, Ixora, Oleander and Poinsettia planted with it, is very effective and also attracts butterflies and encourages them to stay in the farm area.

\section{Rearing problems}

To ensure an optimum butterfly harvest, a great deal of care needs to be taken at various stages in the life cycle. The eggs are very vulnerable to attack by birds, ants and other insects. Many farmers deal with this problem by collecting the leaves with eggs on them and placing them on wet rags or moss (to prevent the leaves drying out) in small cages until they hatch. Others cover the branches of the host tree with nets. Young larvae are easily damaged and need to be transferred with a fine paint brush to their food plants. It takes a lot of patience to persuade a 1-mm long larva to walk on to a fresh leaf. If the larvae are reared on shoots of their food plants in bottles of water, these must be sealed as larvae invariably walk down the stem into the water and drown. It is also essential to arrange the shoots so that some touch the floor, so that when larvae fall they will be able to climb back.

Final instar larvae often change their feeding habits; many start eating shoots and stems, and the birdwings in particular have been known to eat through a $50-\mathrm{mm}$ Aristolochia vine, causing the death of younger larvae feeding above it.

\section{Harvesting methods}

Once the farm is well established, pupae are inspected daily and those that have been there for at least two days, and therefore hardened, are carefully collected by snipping off the shoots to which they are attached. The pupae themselves 160

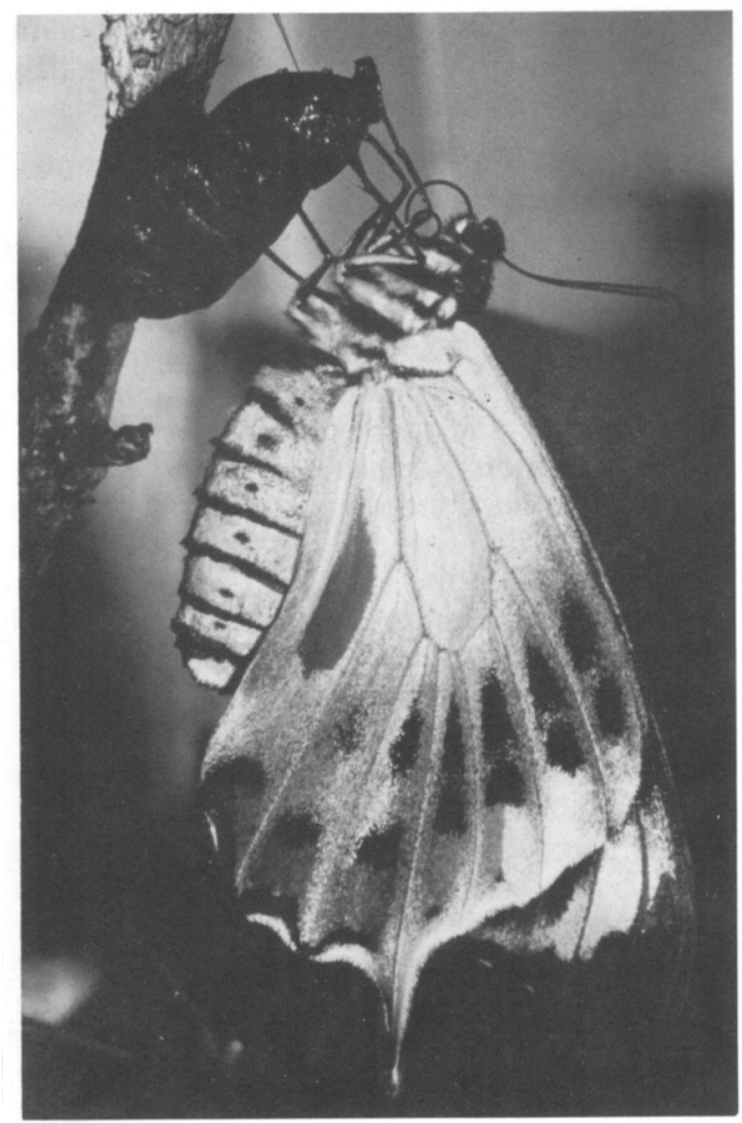

Newly emerged female Papilio laglaizai, drying its wings (Angus F. Hutton).

are not touched as this could damage the future adult. Pupae too high up to reach are left to emerge naturally and fly off to mate and repopulate the farm. Ideally, about 50 per cent should be left as breeding stock. The pupae are carefully pinned or tied, right way up, to a fabric bag or mosquito netting in rows spaced about 50-75 mm apart. Most farmers build a simple 'bush house', with a thatched roof and woven walls lined with wire netting to keep out rats, birds and frogs, in which the pupae are hung. The pupae are lightly sprayed with water each evening to prevent them drying out and to speed up metamorphosis. If moulds develop, usually due to over-watering, the infected pupae must be removed immediately and those remaining transferred to a new hanger and the old one bumt, or

Oryx Vol 19 No 3 


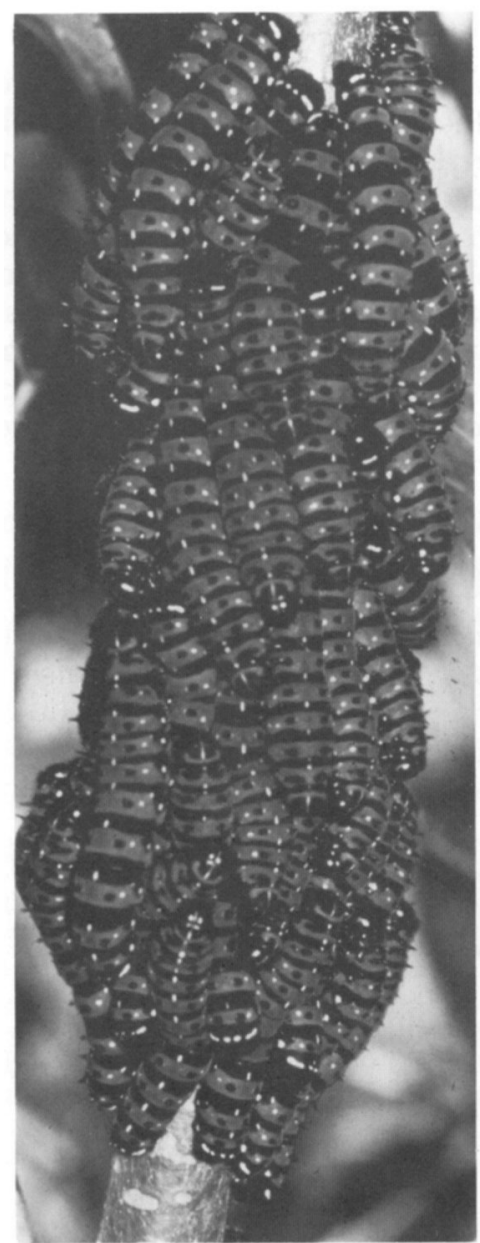

The gregarious larvae of Papilio laglaizai at rest on their foodplant. They are eaten by indigenous people throughout their range. The gregarious habit is probably unique among Papilionidae (Angus F. Hutton).

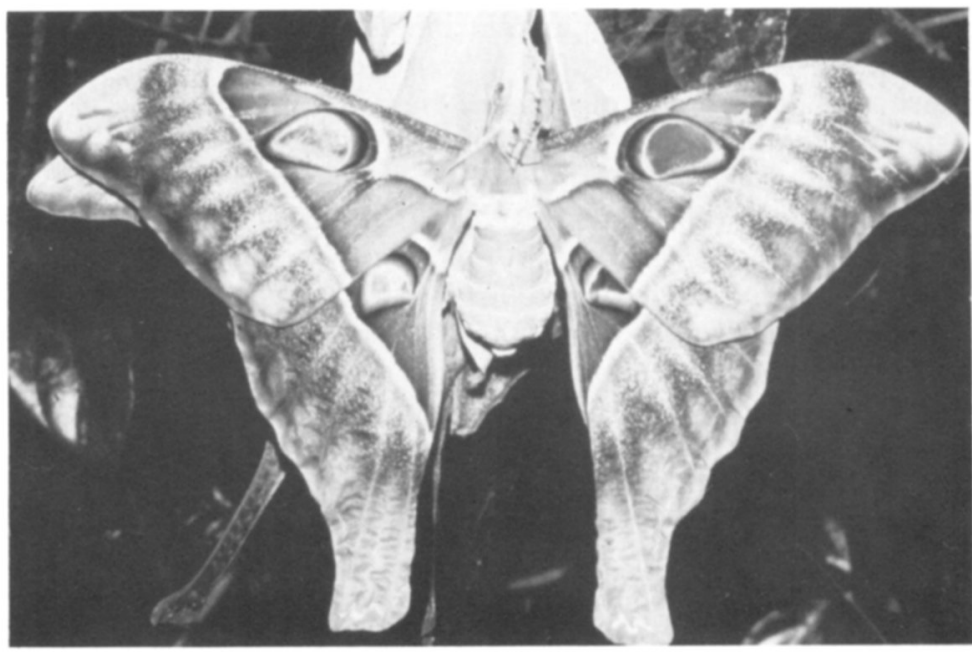

A freshly emerged female Cosinocera hercules-the largest moth in the world, with a 290 -mm wing-span. She is mating with a male, smaller and narrow-tailed, which had picked up her scent and flown in from the wild (Angus F. Hutton)

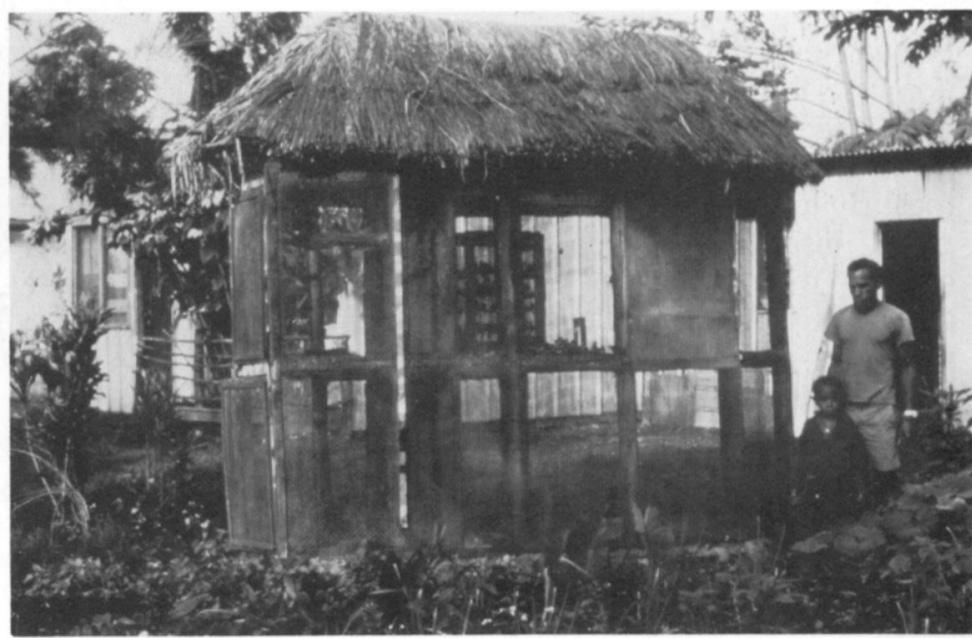

Butterfly farmer and co-operative organiser, Martin Kunma, with his butterfly house and hatching box. These are often used communally (Angus F. Hutton). fresh pupae could be infected later on. As smoke from fire is lethal, it is not usually satisfactory to keep cages of pupae within the farmer's house, although some farmers do so in a protected area well away from the cooking fires. They must be out of the wind, shaded from the sun, and protected from ants.

Pupae due to hatch are transferred to a darkened hatching box, so that emergence occurs in dim lighting conditions where the insects remain calm Butterfly farming in Papua New Guinea and will not flap their wings and damage themselves. After the hardening period of up to four hours, the butterflies can be carefully caught by the thorax-preferably with forceps so that the delicate wings are not touched, and then killed by injecting them with a little boiling water or ethyl acetate. Any imperfect specimens are released.

The farmer packs the dead butterflies carefully in paper triangular envelopes, which are supplied to the farmers at cost. The papered specimens are 
dried in the sun on a simple solar drier made from black plastic sheeting for up to four days. Most farmers have a junior member of the family constantly tending the drier, turning over the envelopes from time to time and being ready to cover them if rain threatens. Those specimens that are fully dry are put into wooden storage boxes, which contain naphthalene to discourage ants and chlorocreasol or thymol to discourage mould. When the farmer has enough specimens, he packs them in specially designed cardboard boxes (supplied by the Agency and reusable) with naphthalene and cotton wool (or more commonly farm-produced kapok) and sends them to the IFTA at Bulolo in the central part of Papua New Guinea. The farmer receives on average some $A \$ 50.00$ per box, and many good farmers send at least one box a week.

\section{Conclusions}

Papua New Guinea has, by balancing the protection of its threatened species with the exploitation of its insect resources for the benefit of its people, given an outstanding lead to other tropical countries. By turning often spectacular, yet commonplace, insects into a cash crop, villagers are earning money as well as satisfying overseas demands at a non-inflated price, thus participating in a rational wildlife management programme that is helping to save not only endangered species of insects and indirectly other wildlife such as birds and mammals, but more importantly the natural habitat itself, both of primary forest and secondary bush. The income returned to the villagers makes the programme attractive, as in many cases isolation, altitude and climate make any agricultural enterprise uneconomic and, in a country that has few roads and still depends on air transport, costs are very high for freight. Insects have a light weight, low volume, and high return potential if managed properly.

In addition major research programmes are being undertaken into several highly endangered species currently protected by law and included in Appendix II of The Convention on International Trade in Endangered Species of Wild Fauna and Flora (CITES). A full-time entomologist has spent several years working with the IFTA looking into 162 all aspects of insect and habitat conservation.

There is considerable potential for similar programmes in other areas of the world. The publication of a booklet on the programme (Anon., 1983) has elicited a great deal of interest and enquiries from other countries including Indonesia, the Solomon Islands, India and some South American countries. Although Malaysia and Taiwan have long had a butterfly industry (largely based on low-grade, wild-caught specimens), they too could benefit from the introduction of farming.

Dr M. G. Morris (1983) has since drawn attention to the PNG industry and the problems in introducing its principles to new countries:

'At the moment, the greatest need seems to be for expertise to instruct would-be butterfly farmers in different countries, and to bridge the gap between government departments-understandably bemused by this novel form of agriculture-and these farmers.'

'Practical instruction on the ground will always be needed, as well as a good handbook, and this may be less easy to provide, though it could be included in agricultural aid programmes involving the developed countries. Certainly the prospects for butterfly farming are bright: future development of farming should be good for the farmers, the customers - and the butterflies!'

\section{References}

Anon. 1983. Managing Tropical Animal Resources: Butterfly Farming in Papua New Guinea. Report of an Ad Hoc Panel of the Advisory Committee on Technology Innovation, Board on Science and Technology for International Development, Office of International Affairs, National Research Council in Cooperation with the Insect Farming and Trading Agency, Bulolo, Papua New Guinea. National Academy Press.

Morris, M.G. 1983. Cashing in on the Insect Trade. International Agricultural Development, March/April.

Wallace, A.R. 1869. The Malay Archipelago. John Murray, London.

Angus, F. Hutton, Garaina Farms, Scrubby Creek Road, Gympie, Queensland 4570, Australia.

The author of this paper is available as a Consultant for the $\mathrm{UN} / \mathrm{FAO}$ to give advice and provide instruction anywhere in the world into the techniques involved in butterfly farming, as well as to train wildlife officers to run their own countries' projects. In April/May 1985, he assisted the Indian Government to set up some pilot butterfly farms in tribal areas. 